\title{
Social Role for the African American Males Behavioral Health Issues, Anxiety Related of the Young
}

\author{
Arthur Horton* \\ Professor, Lewis University, USA \\ *Corresponding author: Arthur Horton, Professor, Lewis University, Romeoville, Illinois, USA \\ Submission: 眥 August 23, 2017; Published: 眥 October 03, 2017
}

\section{Abstract}

Drugs and Violence in Black America What Can Be Done?

Nationally, 55 percent of black men live below the poverty level. In Chicago, 21 percent don't work, and 20 percent have less than a high school diploma. It's not an ideal picture; the street culture of distribution illicit drugs, robbery and black on black violence as one manifestation of that harsh environment in the inner citv of urban America (Figure 1 \& 2).
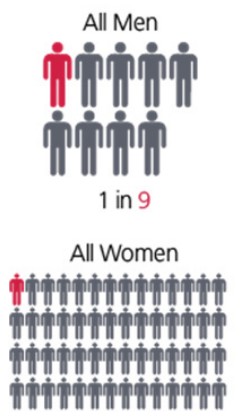

1 in 56

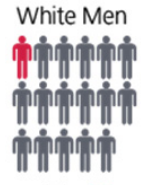

1 in 17

White Women

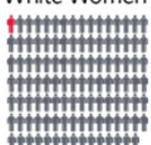

1 in 111

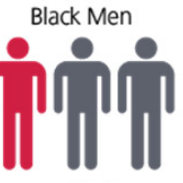

1 in 3

Black Women

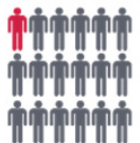

1 in 18

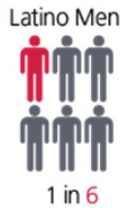

Latina Women

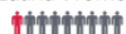

tiving

intrintinit inthintiv thrthintin 1 in 45

Figure 1: The pre, post and adjusted post test mean values of experimental group and the control group on arm strength.

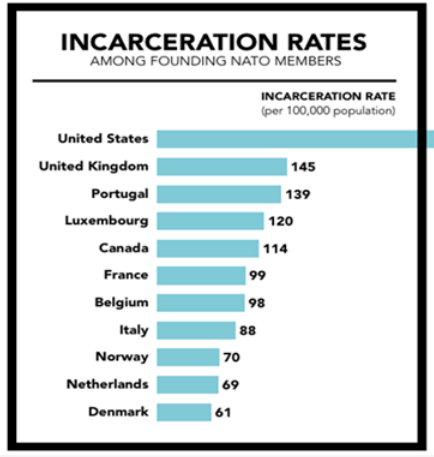

Figure 2: Incarceration Rates among founding nato members.

the entire population. Minorities are disproportionately affected by these incarceration rates, which mean that it's largely minority communities being torn apart by the criminal justice system. When looking at incarceration, black men have a 1 in 3 chance of being imprisoned, while white men have a much lower likelihood of 1 in 17 [2]. There are a many factors why this disparity occurs. However, I draw upon psychoanalytic insights as primary any others as secondary (Figure 3).

Lifetime Likelihood of Imprisonment for those Born in 2001 (Figure 1)

As a case I present the following:

Chicago police issued a warning Saturday about a string of robberies over the last month, including one in which a boy as young as 6 years old displayed a handgun. In each incident, three to nine offenders approached the victims on the sidewalk, in a parking lot and in the hallway of a residential building and either demanded or forcibly removed property before fleeing on foot, according to a community alert from Chicago police. 
Top News: North Korea Tensions and Northern Irish Bonfires In the most recent robbery on June 29 , authorities said a boy believed to be between the ages of 6 and 8 displayed a silver handgun and demanded money [3].

The incidents occurred in the Douglas and Bronzeville neighborhoods on the city's South Side as follows:

- $\quad$ At 3 p.m. on June 3 in the 2900 block of S. Martin Luther King Dr.

- $\quad$ At 9 p.m. on June 3 in the 2900 block of S. Michigan Ave.

- At 2:15 p.m. on June 4 in the 2900 block of S. Michigan Ave.

- At 6 p.m. on June 4 in the 2700 block of S. Indiana Ave.

- At 10:30 p.m. on June 3 in the 2600 block of S. Michigan Ave.

- At 4:45 p.m. on June 7 in the 2900 block of S. Indiana Ave.

- $\quad$ At 8:30 p.m. on June 7 in the 2900 block of S. Martin Luther King Dr.

- At 9:30 p.m. on June 8 in the 2900 block of S. Martin Luther King Dr.

- At 4:10 p.m. on June 9 in the 0-100 block of W. 30th St.

- At 6 p.m. on June 26 in the 2900 block of S. Martin Luther King Dr.

- At 7:57 p.m. on June 28 in the 0-100 block of E. 29th St.

The suspects were described as black males between 6 and 20 years old, according to police investigators. Quite often perpetrators of such crimes have a history of street gang affiliation and drug use starting at an early age [4].

High rates of suspensions and expulsions for certain groups-particularly African-Americans, Hispanics, and those with disabilities-are evident in data gathered nationally by the Department of Education's Office for Civil Rights (OCR). Data from 72,000 American public schools in the 2009-10 school year, for example, show that while African-Americans make up 18 percent of the students in this large sample, they account for 46 percent of students suspended more than once, 39 percent of students expelled, and 36 percent of students arrested on campus. White students, by contrast; represent 29 percent of multiple suspensions and 33 percent of e expulsions-but 51 percent of the students [3]. For some not beings engaged by school(student life including extracurricular sports, etc) due to court appearances or becoming progressively indifferent toward academic requirements with the classroom being a source for frustration and anxiety, criminal activity become alternative to being in school.

\section{The Freudian Perspective}

Certainly it was Freud who made us realize that how one feels is as important in describing a human experience as are the facts a person's life. Starting in the 1890s, in a bid to cure "nervous disorders", Freud began describing what remains the most comprehensive and revolutionary theory of the mind ever proposed. At its core was Freud's notion that the source of his patients' ills lay in the unconscious -- a shrouded realm of thought, fantasies, memories and dreams embedded in childhood and radiating control over one's feelings and actions for life.

Freud theorized that by identifying and exploring past experiences and accepting their sovereignty over one's life, a person can gain relief from a wide range of emotional problems. Although Freud did not discover the unconscious, his insight into its makeup was brilliant and original. "His contribution was to take a shadowy... poetic notion, lend it precision, and make it into the foundation of a psychology by specifying (its) origins and contents and its imperious ways of pressing toward expression," writes Peter Coy in his 1988 biography Freud: A Life for Our Time. From what his patients were dredging up, Freud began piecing together the idea that a nervous disorder, a "neurosis", resulted from the bottling-up of traumatic thoughts too painful to acknowledge. The unconscious was something that had long been discussed; it was common coin for philosophers and poets. But Freud identified the existence of repression -- the fact the human mind will forget, distort, or deny real experience in an effort to defend itself. Most controversial about Freud's theory was that the unconscious was filled with repressed sexual wishes and fantasies that people experience when they are young children.

In 1989, with the publication of his book The Interpretation of Dreams, Freud described exactly how the repressed impulses cause psychic damage. He found it by studying his patients' dreams, which he called the "royal road to the unconscious."Freud explained that dreams are distorted images that result when repressed but powerful impulses -- the mind's id -- surge toward consciousness only to be, pushed back by the mind's protective defense system -- the super-ego, or conscience. This conflict, if never openly identified, can cause severe mental blocks -- neurotic behavior such as the inability to form a lasting relationship, difficulty succeeding at work, unexplained anxiety, and even physical illness.

By 1923 Freud had published The Ego and the Id, which fully explained his theory of the mind as divided into three forces --the id, ego and super-ego. It was Freud who explained why a young woman, ruled by a dominating father, would marry an abusive man. The woman, says Freud, is destined to repeat bad relationships until the original experience with her father is dredged up from her unconscious. Perhaps Freud's greatest contribution is the convincing claim that we are not completely the masters of our psyches.

But the most significant development in the recent history of psychology, and perhaps the most important advance in the field since Freud, has been the work of Stanislov Gruf. Gruf began as a psychoanalytic psychiatrist, and the original background of his ideas was Freud's biological and biographical perspective, though on a much deeper stratum of the psyche than Freud had recognized. The basis of Gruf's discoveries was his observation of several thousand psychoanalytic sessions, first in Prague and then in Maryland with 
the National Institute of Mental Health, in which subjects used extremely potent psychoactive substances, particularly LSD and then later a variety of powerful non-drug therapeutic methods, which served as catalysts of unconscious processes. Gruf found that subjects involved in sessions tended to undergo progressively deeper exploration of the unconscious, in the course of which there consistently emerged a pivotal sequence of experiences of great complexity and intensity. In the initial sessions, subjects typically moved back through earlier an earlier biographical experiences and traumas -- the Oedipus complex, toilet training, nursing, early infantile experiences -- which were generally intelligible in terms of Freudian psychoanalytic principles and as confirmation of Freud's theories. But after reliving and integrating these various memory complexes, subjects regularly tended to move further back into an extremely intense engagement with the process of biological birth. Subjects reported that experiences at this level possessed intensity and universality that far surpassed what they had previously believed was the experiential limit for an individual human being. These experiences occurred in a highly variable 54 order, and overlapped with each other in very complex ways, but abstracting from this complexity Gruf found a distinct sequence - $\neg$ which moved from an initial condition of undifferentiated unity with the maternal womb, to an experience of sudden fall and separation from primal organism unity, to a highly charged life - and-death struggle with the contracting uterus and the birth canal, and culminating in an experience of complete annihilation. This was followed almost immediately by an experience of sudden, unexpected global liberation, which was typically perceived not only as physical birth but also as spiritual rebirth, with the two mysteriously intermixed.

A host of implications follow from Gruf's work -- insight concerning the roots of male sexism in the unconscious fear of female birthing bodies; concerning the roots of the Oedipus complex in the far more primal and fundamental struggle against the seemingly punitive uterine contractions and constricting birth canal to regain union with the nourishing maternal womb; concerning the therapeutic importance of the encounter with death; concerning the roots of specific psychopathological conditions such as depression, phobias, obsessive-compulsive neuroses, sexual disorders, sadomasochism, mania, suicide, addiction, various psychotic conditions, as well as collective psychological disorders such as the impulse toward war and totalitarianism.

Despite the profundity of Gruf's contribution to the understanding of the genesis of the emotional self there are many questions to be raised with new advances in the sciences. In just a decade the facts of life have changed. Doctors can now grow embryos, clone them, nurture them in test tubes and freeze them for later use. They can grow palm-size preemies to maturity in artificial wombs. These technologies now exist separately, but eventually they will intersect and when they do, there will be a revolution in parenting in the very definition of family, unparalleled in history. We will be able to conceive an embryo in the lab, test it for genetic health and put it into a machine to mature. Scientists are working on the next generation of neonatal incubators -- true artificial wombs in which the fetus will be submerged in liquid.
Soon post- modern society will be able to have babies that come to term completely outside a woman's body. We can only speculate about the emotional development of individuals in that brave new world. And this brave new world is only a few decades away. The likelihood is that we will have these capabilities by the year 2030 .

According to Freud, "When the ego is forced to acknowledge its weakness, it breaks out into anxiety: reality anxiety in face of the external world, normal anxiety in face of the super ego, and neurotic anxiety in face of the strength of the passion in the id." Freud also identified instinctual anxiety what is currently spoken of as fight or flight response to certain stressors [1].

Contemporary psychiatry has advanced for diagnostic purposes clinical criteria to identify "personality disorders." The development of an individual as to one of the recognizes personality types entails biology and temperament, agency and a desire to be affiliated with other people, anxiety and harm avoidance patterns, and intra / interpersonal neurobiology.

\section{Treatment strategies for antisocial personality disorder (APD) are suggested as follows}

Anxiety and APD:

a. Develop harm avoidance life manage skills

b. Utilize active relaxation techniques

c. Increased awareness of anxiety in disguise

d. Find anxiety source(s) and tame them

e. Manage anger with anger diary

f. Use anger escalator tools for anger management

Depression and APD:

a. Recognize this of hidden emotion

b. Understand the cost-benefit of behaviors

c. Use HALT tips(privately to yourself or openly to others)

Interpersonal relationships and APD:

a. Turn agency into positive paths

b. Journaling to identify implicit memory to increase awareness

c. Train the "wise mind" for better self-control

d. Storytelling for attunement and empathy

In conclusion, this not just a story of the relatively high levels of incarceration of African American males at most level of government prisons or jails in the states in which they reside nor the invisibility of elderly Black males and even those to that time in life in civic, private and public sector in the various regions of the nation [1,5-11]. The overall damaging consequence has been the decline of opportunity to improve one's status and a lack of African American social mobility. It also might mean that people in poor neighborhoods end up in a self reinforcing cycle of under-funded 
Schools, high crime and social breakdown [5-7,9]. Despite what appears to be a bleak portrait of African American family life, it is also true that resilience and cultural strength has enabled members of the African American population to "to keep on keeping on".

\section{References}

1. Craig Haney, Philip Zimbardo (1998) New Introductory Lectures on psychoanalysis: The Problem of Anxiety. In: Haney C, Zimbardo D (Eds.), The Past and Future of U.S. Prison Policy: Twenty-five Years after the Stanford Prison Experiment American Psychologist 53(7): 709-727.

2. Mason CA, Chapman DA, Chang S, Simons J (2003) Impacting Re-Arrest Rates Among Youth Sentenced in Adult Court: An Epidemiological Examination of the Juvenile Sentencing Advocacy Project. J Clin Child Adolesc Psychol 32(2): 205-214.

3. Horton A (2017) Chicago: A city in crisis, the need for healing. Ment Health Addict Res 2(1): 1-8.

4. Thomas MC, Day-Vines NL (2010) Culturally competent collaboration: school counselor collaboration with african american families and communities. Professional School Counseling 14(1): 53-63.
5. Horton A (2013) African American Male Drug Use and Gambling and Criminal Behavior, the Need for More Effective Treatment. J Alcoholism Drug Depend 1(6): 1-3.

6. Horton A (2007) Murder in the City; Embedded, Intractable, and Treatment Resistant. Journal of Human Behavior in the Social Environmnent 16(3): 15-31.

7. Horton A (2002) Violent crimes and racial profiling: what the evidence suggests. The Journal of Human Behavior in the Social Environment 6(4): 87-106.

8. Sue DW (2010) Microagressions in everyday life: Race, Gender, and Sexual Orientation. John Wiley \& Sons, New Jersey, USA.

9. Hill P (1992) Coming of Age: African American Male Rites of Passages, African American Images, Chicago, USA.

10.Welch R, Angulo CT (2000) Justice on Trial: Racial Disparities in the American Justice System: Leadership Conference on Civil Rights/ Leadership Conference on Education Funds, Washington, USA.

11.Wilson AN (2011) Black on Black Violence: The psychodynamics of black self-annihilation in service of white domination. African World Info Systems, New York, USA. 